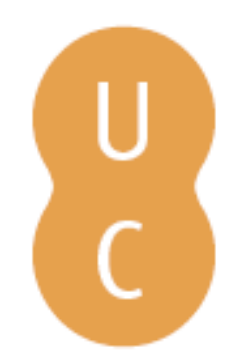

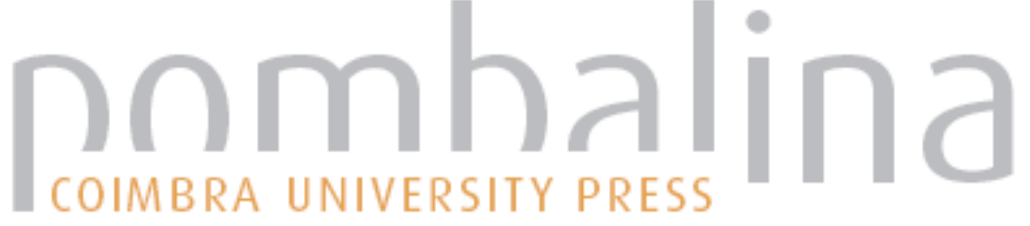

\section{E os clássicos se fizeram um absurdo...}

Autor(es): $\quad$ Santos, Ana C. Fonseca dos

Publicado por: Centro de Estudos Clássicos e Humanísticos da Universidade de

Coimbra; Imprensa da Universidade de Coimbra

URL

persistente: URI:http://hdl.handle.net/10316.2/30287

DOI: $\quad$ DOI:http://dx.doi.org/10.14195/978-989-721-038-9_57

Accessed : $\quad$ 26-Apr-2023 16:05:58

A navegação consulta e descarregamento dos títulos inseridos nas Bibliotecas Digitais UC Digitalis, UC Pombalina e UC Impactum, pressupõem a aceitação plena e sem reservas dos Termos e Condições de Uso destas Bibliotecas Digitais, disponíveis em https://digitalis.uc.pt/pt-pt/termos.

Conforme exposto nos referidos Termos e Condições de Uso, o descarregamento de títulos de acesso restrito requer uma licença válida de autorização devendo o utilizador aceder ao(s) documento(s) a partir de um endereço de IP da instituição detentora da supramencionada licença.

Ao utilizador é apenas permitido o descarregamento para uso pessoal, pelo que o emprego do(s) título(s) descarregado(s) para outro fim, designadamente comercial, carece de autorização do respetivo autor ou editor da obra.

Na medida em que todas as obras da UC Digitalis se encontram protegidas pelo Código do Direito de Autor e Direitos Conexos e demais legislação aplicável, toda a cópia, parcial ou total, deste documento, nos casos em que é legalmente admitida, deverá conter ou fazer-se acompanhar por este aviso.

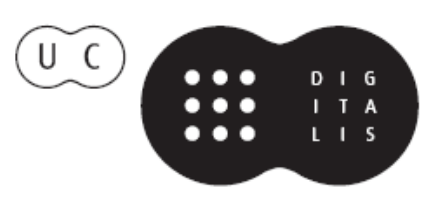




\section{De ayer a hoy}

\section{Influencias clásicas en la literatura}

\section{Aurora López, Andrés Pociña, Maria de Fátima Silva (coords.)}




\section{E os CLÁSSICOS SE FIZERAM UM ABSURDO...}

Ana C. Fonseca dos Santos Universidade Federal de Minas Gerais

Aqui refletimos sobre o diálogo que a peça Que venha a Senhora Dona, do académico Jacyntho Lyns Brandão, mantém com o teatro do absurdo e com Alceste, de Eurípides. Ambas apresentam semelhanças estruturais e de enredo: ambas tratam da busca de um substituto para alguém que vai morrer: mostram, de forma realista e satírica, a angústia e o medo humanos diante da inevitável morte. A Senhora Dona se aproxima do teatro do absurdo. $\mathrm{O}$ absurdo da morte ou a morte no teatro do absurdo? É possível abordar a inquestionável Senhora Dona Morte pelo viés do absurdo? É possível (re)ler o teatro antigo nessa perspectiva?

Nosso trabalho tem por objetivo refletir sobre o diálogo que a peça vencedora do Concurso de Textos Teatrais do Palácio das Artes, Belo Horizonte, Minas Gerais, de 1980, Que venha a Senhora Dona, do acadêmico Jacyntho Lins Brandão, professor de língua e literatura grega, mantém com o teatro do absurdo e com a obra Alceste, de Eurípides.

As duas peças apresentam, além de semelhanças estruturais, um enredo bem parecido: ambas se constroem em torno da busca de um substituto para alguém que vai morrer. Em Alceste, é o general Admeto, na Senhora Dona vemos um pai à procura de alguém que possa morrer no lugar de seu filhinho ainda bebê.

Assim como a peça euripidiana, a brasileira, Que venha a Senhora Dona, é uma obra que rejeita classificações. Não possui - em termos de teatro antigo e mesmo do teatro contemporâneo - as características de uma comédia, nem de uma tragédia, nem de um drama (sequer o satírico como é o caso de Alceste). Falta às duas, por exemplo, o registro de uma linguagem que oscile entre o tom elevado e o baixo, faltam-lhes - no sério assunto acerca da morte - o tom solene esperado. Entretanto, ambas as peças possuem elementos dramáticos e satíricos, como, por exemplo, uma personagem que possui a irreverência e a desmedida dos híbridos de Dioniso. Como muito bem observou Moreira:

Tomando Alceste como drama satírico, precisaríamos resolver os problemas técnicos em relação ao coro - que não se apresenta formado por sátiros, uma vez que nem sequer o pai Sileno entra em cena -, afirmando que Héracles, embriagado e voraz, substitui a raça dos híbridos de Dioniso, encarnando a irreverência e a desmedida atribuída a eles, pois em meio ao drama da casa de Admeto o herói canta e bebe descontraidamente ${ }^{1}$.

\footnotetext{
${ }^{1}$ Moreira, Flávia, Leituras da Morte, p. 170.
} 
Quanto à peça brasileira, temos Teteca, uma menina muito viva e faladeira que, por ser criança e "ter problema" (como definem as personagens Inacinha e D. Inocência), não tem sobre si as expectativas de discrição que pesam sobre os adultos. Teteca goza de um menosprezo por parte dos familiares.Desconsiderada, como Héracles no contexto da criadagem da casa de Admeto, lhe é permitido explicitar e expor os problemas que são apresentados veladamente pelos outros personagens. Em sua condição de deslocadas (personagens que não pertencem, não se adaptam às normas sociais ou de etiqueta), Teteca e Héracles têm a liberdade de fazer o papel de sátiros nas peças estudadas.

Ambas mostram, de forma realista e contundente, irônica e satírica, a angústia e o medo humanos diante da morte, inevitável a todos os seres viventes. Naturalmente, por uma ser mais de 2000 anos mais nova que a outra, por ser o local de enunciação para uma peça a Grécia, para a outra o Brasil das Minas Gerais, temos obviamente formas diferentes de tratar o mesmo tema, o mesmo sentimento. Entretanto, o que esse trabalho pretende analisar é que, por mais que seja natural que elas sejam diferentes quanto à forma, essa forma se sustenta num substrato comum e por isso não é tão diferente assim. Que isso seja apenas porque o autor brasileiro tenha lido o grego nos parece um argumento bastante fraco. As duas peças são - consideradas as distâncias de tempo e espaço -, marcadas pelas mesmas exceções, a mesma difícil classificação. Acreditamos que elas possam ser lidas como "expressão de seu tempo" ou expressão de um tempo de crise de valores. Para embasar essa hipótese, daqui por diante nos serviremos dos teóricos do Teatro do Absurdo e iniciamos com palavras do húngaro-inglês Martin Julius Esslin, professor de arte dramática que por primeiro utilizou a expressão Teatro do Absurdo. Ele afirma:

Cada um desses componentes do panorama cultural de uma época encontra sua própria expressão artística; o Teatro do Absurdo, no entanto, pode ser identificado como um reflexo do que parece ser a atitude mais autenticamente representante do nosso tempo ${ }^{2}$.

Que venha a Senhora Dona, escrita e encenada no mesmo ano de 1980, apresenta, em sua linguagem, certa semelhança com o teatro do absurdo. Naturalmente, sendo uma obra do nosso tempo, expressa esse tema tão universal, a angústia humana diante da morte, sob a ótica atual. E que forma melhor de fazê-lo do que dialogando com o teatro do absurdo, que deu um passo à frente do teatro existencialista, alinhando forma e conteúdo quando decidiu falar sobre o absurdo da condição humana, sobre a falta de

${ }^{2}$ Esslin, O teatro do absurdo, p. 19. Nosso tempo aqui significa certamente o tempo do autor, a saber, seu período de vida que vai de 1908 a 2002. 
sentidos - de certezas, de pressupostos básicos - tão característica do nosso tempo?

De fato o que nos parece e o que tentamos aprofundar nessa pesquisa ainda iniciante é a pertinência e dependência mesma do teatro contemporâneo em relação ao teatro antigo. À primeira vista estaríamos dizendo um absurdo dos absurdos, entretanto, não estamos sós. Hans-Thiers Lehmann em seu Teatro pós-dramático ${ }^{3}$ utiliza-se da noção de chora para o teatro contemporâneo. Esse complicado termo filosófico aparece pela primeira vez em Platão, no diálogo filosófico Timeu. Grosso modo, podemos entender chora como a região onde ficam todas as ideias, todas as coisas que só existem em potência. Acessáveis, mas ainda não acessadas, pela palavra. Deleuze em seu $O$ esgotado nos apresenta a ideia contrária: a de um ser muito mais do que cansado, tão exausto que se torna esgotado - aquele que esgotou toda a possibilidade. A chora de Platão seria a ideia que, explicita ou implicitamente, paira sobre o teatro que segue a convenção tradicional, inclusive o teatro existencialista de Sartre e Camus. Já o esgotado de Deleuze é a ideia que serve de base ao teatro do absurdo: a possibilidade esgotada, a ação vazia de significado, sustentada somente pela linguagem. No entanto, a linguagem, nesse caso, não é acessada para organizar o real e nomear o possível: é apenas a linguagem em si, vazia, a mais crua exposição do absurdo da condição humana. Segundo Esslin:

$\mathrm{O}$ Teatro do Absurdo desistiu de falar sobre o absurdo da condição humana; ele apenas o apresenta tal como existe - isto é, em termos de imagens teatrais concretas 4 .

Dessa forma, nas duas obras analisadas temos a mais absurda das situações: alguém tem que fazer o papel de deus e escolher quem morre no lugar de outra pessoa. Ao mesmo tempo em que a situação é completamente surreal, ela mostra, teatral e concretamente, o desespero humano diante do fato mais inevitável da vida: o de que um dia ela termina em morte.

O conceito de esgotamento é claro em Que venha a Senhora Dona (e diríamos que, avant la lettre, também na Alceste euripidiana), mesmo que não seja levado ao extremo, mesmo que não seja explicitado, como o é no teatro de Samuel Beckett. Os personagens, presos na situação de ter que escolher alguém para morrer no lugar da criancinha que ainda sequer teve tempo de viver, executam no palco uma ação feita somente de linguagem: atiram flechas de palavras uns contra os outros, acusações tolas, incomprováveis, incoerentes. A charada, "exercício de lógica" apresentado por Cibele, é parodiada dezenas de vezes: a cada vez é uma personagem diferente que brinca com o texto, e, mudando um detalhe aqui e outro ali, faz com que o sentido trabalhe a seu

\footnotetext{
${ }^{3}$ Tradução de Pedro Süssekind, São Paulo, Cosac e Naify, 2007, pp. 246-247.

${ }^{4}$ O teatro do absurdo, p. 21.
} 
favor, mesmo que o sentido assim criado não passe de um sofisma. Ainda segundo o professor húngaro-inglês:

O Teatro do Absurdo, por outro lado, tende para uma desvalorização radical da linguagem, para a poesia que deve emergir das imagens concretas e objetivadas do próprio palco. O elemento da linguagem ainda desempenha um papel importante nessa concepção, mas o que acontece no palco transcende, e muitas vezes contradiz, as palavras ditas pelas personagens.

De fato, em Alceste temos a linguagem minuciosamente trabalhada e poética, característica do dramaturgo grego. Contudo, mais importante que a linguagem nos parece ser, também nesse caso, a ação. Não é por acaso que a imagem de Tanathos que permaneceu para a posteridade tenha sido a que Eurípides the deu nessa peça - vestido de negro. A iconografia anterior the dava uma aparência muito bela e clara, como a de Morfeu. Mas Alceste sendo buscada por uma figura tão assustadora, ainda nos braços do marido, the concedendo mais alguns anos de vida, é belíssima. Um Tanathos claro e belo não causaria tanto pavor, não evidenciaria toda a beleza e finitude da vida.

A peça brasileira se encaixa melhor na definição oferecida por Esslin. Sua linguagem é simples, cotidiana, não causa atrito aos ouvidos belo-horizontinos (público ao qual se destinava quando foi encenada). Combinada com a ação, entretanto, produz uma poesia belíssima. A cena familiar provoca uma sensação de proximidade, e, combinada com os dramas tratados (tão comuns entre tantas famílias) - os ciúmes, as invejas, os desentendimentos, as preferências, as críticas -, se torna poética na medida em que mostra a condição humana, em toda a sua solidão e coletividade, em todo o seu paradoxo. Nessa, sim, as ações contradizem as palavras, e isso contribui para que a peça seja não mais incoerente, mas mais enfática, pois une a forma ao conteúdo.

Um pouco mais difícil - mas não impossível - é ir além, e propor leitura semelhante sobre Alceste. De fato, é uma peça escrita e encenada milênios antes do conceito de Teatro do Absurdo. Se ele é uma das expressões mais autênticas da atualidade, pode ser aplicado a uma obra da Antiguidade Clássica? Acreditamos que pode. Embora a elaboração desse conceito seja bem recente, ainda que só agora tenhamos refletido sobre o esgotamento, todos os elementos que compõem o Teatro do Absurdo (a sensação de fastio, de relativização e queda dos valores) existia, com menor ou maior intensidade, desde os tempos da Grécia Arcaica. Mesmo na comédia antiga não é difícil encontrar exemplos de uso sofisticado da linguagem para criar absurdos.

Sendo assim, não propomos aqui que o teatro clássico se encaixe no Teatro do Absurdo. Nem nossa pesquisa foi suficientemente extensa para poder afirmar que o teatro clássico dialoga com o teatro do absurdo. Estamos, sim, querendo

\footnotetext{
${ }^{5}$ Esslin, O teatro do absurdo, p. 22.
} 
afirmar que Alceste dialoga não só com a Senhora Dona de Brandão, mas também com o teatro do absurdo. A partir desse ponto abre-se a possibilidade de que outras peças clássicas possam ser lidas da mesma forma.

$\mathrm{O}$ desfecho de Alceste, que a princípio tendemos a considerar como o final feliz esperado de um drama satírico, é dúbio. A peça termina com um rei marcado pela pecha de covarde, um reino marcado pelo profundo luto pela excelente rainha, e uma rainha ainda muda como as sombras da terra dos mortos. Sim, o corpo de Alceste retornou, mas sua alma ainda é a mesma? Ela se lembra de quem é? Ela poderá, algum dia, voltar a falar? Ela conseguirá se recuperar da assustadora experiência de ter morrido? Não sabemos.

Ao que nos parece, Eurípides, de uma forma muito sofisticada, trabalhou a linguagem de sua obra tão sutilmente que a princípio não se percebe o absurdo criado. Ele, porém, está lá: o absurdo da condição humana já referido por Héracles algumas cenas antes, quando faz um discurso sobre a finitude da vida humana, e sobre como não se deve levar muito a sério a morte de uma estrangeira.

Enxergar uma peça tão antiga como Teatro do Absurdo faz com que observemos por outro ângulo as obras clássicas. Olhar por outro ângulo, na esmagadora maioria das vezes, permite novas descobertas. Acreditamos que ver Alceste dessa forma ajuda a entender por que as peças de Eurípides foram preservadas, lidas e encenadas por mais de dois milênios. $O$ fato de uma teoria tão moderna poder se aplicar a uma obra tão arcaica mostra o quanto ela é universal. $\mathrm{O}$ quanto, mesmo que a própria cultura em que foi criada tenha se perdido, ela fala aos muitos públicos a que foi apresentada. O quanto ela é capaz de falar a qualquer pessoa.

Ao mesmo tempo, mostra que o autor, ainda que não tenha refletido sobre isso como fizeram Esslin, Beckett, e outros, sabia mostrar o absurdo humano, e sabia o quanto ver esse absurdo escancarado é importante para os seres humanos, pois a arte serve de espelho para nós mesmos; para que, vendo nossa imagem refletida, nós consigamos nos entender.

A forma leve, delicada e poética com que a peça de Jacyntho Lins Brandão dialoga com Alceste nos mostra, também, a sensibilidade desse autor, a forma como ele compreende o que há de mais universal e interessante no teatro clássico, e é capaz de reproduzir essa universalidade sem, contudo, perder a modernidade. $\mathrm{O}$ jeito contemporâneo de tratar dos mesmos assuntos mostra sensibilidade, também, para com a sua própria era. E, a nosso ver, é a combinação do que há de mais clássico com o que há de mais contemporâneo que faz da peça Que venha a Senhora Dona uma obra-prima da atualidade. 


\section{Bibliografia}

Brandão, Jacyntho Lins, Quevenha a Senhora Dona, Belo Horizonte, Tessitura, 2007.

Deleuze, Gilles, O esgotado, in Sobre o teatro: Um manifesto de menos; O esgotado, Tradução Fátima Saadi, Ovídio de Abreu, Roberto Machado, Rio de Janeiro, Jorge Zahar, 2010.

Esslin, Martin, O teatro do absurdo, Trad. Bárbara Heliodora, Rio de Janeiro, Zahar Editores, 1968.

Lehmann, Hans-Tiers, O teatro pós-dramático, Trad. de Pedro Süssekind, São Paulo, Cosac e Naify, 2007.

Moreira, Flávia Freitas, Leituras da Morte, in: Sousa e Silva, M. F.; Barbosa, T. V. R. (org.), Tradução e recriação, Belo Horizonte, Faculdade de Letras da UFMG, Faculdade de Letras da Universidade de Coimbra, 2010. 